\title{
USE OF MOUTHWASHES IN THE TREATMENT OF CHRONIC CATARRHAL GINGIVITIS IN CHILDREN
}

\author{
Muzaffarov Bekzod Yunusovich ${ }^{1}$, Saidov Akbar Ahadovich ${ }^{2}$ \\ Bukhara state medical Institute, Uzbekistan
}

\begin{abstract}
Inflammatory periodontal diseases are a serious problem of modern dentistry due to the high prevalence, complexity of diagnosis, treatment and rehabilitation of patients. The least studied pathology to date is aggressive periodontitis, in which active destruction of the supporting tissues of the teeth begins at a young age and in a relatively short period of time leads to massive tooth loss [Grigoryan A. S ssoavt., 2004; Dmitrieva L. A., 2007; grudyanov A. I., 2010; Jin L. J. et al., 2011;WolfD.L., Lamster I. B., 2011; Ohrn K., Jonsson V., 2012]. The prevalence of inflammatory periodontal diseases is extremely high and reaches according to various authors from 70 to $98 \%$. In this regard, improving the methods of diagnosis and treatment of these diseases is a serious problem of dentistry.
\end{abstract}

Keywords: periodontal diseases, anaerobic microorganisms, microflora composition, pathogenic microflora.

\section{Introduction}

An important problem is the treatment of the initial forms of periodontal diseases-catarrhal gingivitis, in which dysbiotic processes increase in the oral cavity, caused by the restructuring of the microflora composition towards a significant increase in opportunistic and anaerobic microorganisms, which causes a high frequency of relapses of the disease with the transition to more severe forms (Razina I. N., Chesnokova M. G., 2014;Leonova L. E., Pavlova G. A., Omarova L. V., Barannikov V. G., Kirichenko L. V., Varankina S. A.,2015; villapando et al., 2010; zijnge V., Barbara M.,2010).

Modern mouthwashes improve the cleaning of dental surfaces, prevent plaque formation, deodorize the oral cavity, and contain various biologically active components that contribute to the prevention and treatment of dental diseases (Kuzmina I. N., 2009).

The introduction of antiseptics into the composition of rinses causes their antibacterial activity due to the suppression of growth and reproduction of various representatives of pathogenic microflora (Orekhova L. Yu., 2007, Barnett M. L., 2006, Teles R. P., 2009) and contributes to a significant reduction in the amount of plaque.

\section{Objective}

To Evaluate the effectiveness of oral rinse aid in children with chronic catarrhal gingivitis.

\section{Objective of the study}

To Evaluate the clinical effectiveness of complex therapeutic measures with the use of anti-inflammatory agent "Asepta".

\section{Materials and methods of research}

20 people with chronic catarrhal gingivitis (HCG) took part in solving these tasks. Age of patients from 14 to 18 years: boys $-12(60 \%)$, girls $-8(40 \%)$. The control group consisted of 18 practically healthy individuals.

Patients were examined using the Greene-Vermillion OHI-S hygiene index (1964g). gum bleeding was determined by the modified SBI index according to Muhlemann (1971), gingival edge inflammation was evaluated by the PMA index according to Parma (1960).

In treatment to the patients of the main group KHKG included in the main group of patients we performed intraoral anesthesia of the gingival margin 2\% lidocaine, then the irrigator Waterpik WP-300 irrigated inflamed gums rinse "forest balsam". Metrogil Denta adhesive paste was used as an antibacterial agent. To accelerate the regenerative properties of the gums, patients with HCG were prescribed vitamin A. the Asepta Rinse aid is designed to remove plaque, bacteria, and food residues. The adjustable stream of the irrigator sprays the rinse aid at a certain speed into the affected area and has a favorable effect on the gum tissue: it stimulates metabolism, activates the regenerative processes of the gum tissue. The course of irrigation treatment with the use of Asepta rinse aid is 2 times a day for 30 seconds. The course of application is 14 days, if necessary, repeat after 10 days.

The method of therapeutic treatment was as follows: all patients were given professional oral hygiene, soft and hard dental deposits were removed, carious teeth and their complications were treated, and if necessary, patients were referred to an orthopedic dentist for rational prosthetics.

In the control group, patients with HCG underwent traditional local treatment, which consisted of applying analgesia of the gingival margin with $2 \%$ lidocaine solution, antiseptic treatment with $0.06 \%$ chlorhexidine solution, and applying an antibacterial paste "Metrogil Denta".

When collecting anamnesis, we asked patients about possible causal factors of the disease, the duration of the periodontal inflammatory process, the presence of any diseases of internal organs. Patients often complained of bad breath, bleeding gums when brushing their teeth, or when eating solid food. 
During an objective examination, attention was paid to the color of the oral mucosa and gums, humidity, the state of the gingival papillae, gum margins, dental plaque, the presence of hard dental deposits, and the dental rows were examined.the data obtained were entered into the dental chart developed by us. Patients were examined before treatment, then objective clinical and index indicators were evaluated at the end of treatment.

Treatment results and their discussion.

Initial data on the state of HCG in patients before treatment are presented in table 1.

Table 1.

Initial indicators of the index assessment of patients in the control group $(\mathrm{M} \pm \mathbf{m})$

\begin{tabular}{|c|c|c|}
\hline Indicator & Girls 8 people(40\%) & Boys 12 hours. (60\%) \\
\hline OHIS (points) & $1,0 \pm 0,03$ & $1,1 \pm 0,04$ \\
\hline PMA (\%) & $18,3 \pm 2,8 \%$ & $9,9 \pm 1,2 \%$ \\
\hline SBI (\%) & $7,7 \pm 0,03$ & $8,5 \pm 0,22$ \\
\hline
\end{tabular}

The initial data on the periodontal condition of the control group of patients are presented in table 1. Patients did not complain, the gums were pale pink when examined, and there was no bleeding. Periodontal disease is clinically healthy. Hygiene is satisfactory.

After 14 days of treatment, the state of oral hygiene significantly improved. Along with a significant improvement in subjective feelings, patients noted a positive dynamics of the index score, the absence of gingival inflammation (table 2). none of them had allergic reactions or any adverse side effects. All patients gave a good assessment of irrigation with the Waterpik WP-300 irrigator of the ASEPTA rinse aid»

Table 2

Indicators of index evaluation of patients in the main group 14 days after treatment. $(\mathrm{M} \pm \mathrm{m})$

\begin{tabular}{|l|l|c|}
\hline Indicator & Girls 8 people(40\%) & Boys 12 hours. (60\%) \\
\hline OHIS (points) & $2,01 \pm 0,04$ & $2,07 \pm 0,03$ \\
\hline PMA (points) & $15,3 \pm 2,6 \%$ & $19,3 \pm 1,7 \%$ \\
\hline SBI (\%) & $17,7 \pm 0,02$ & $18,5 \pm 0,12$ \\
\hline
\end{tabular}

When examining patients of the main group, there was no hyperemia or edema of the gums, no bleeding or discomfort. Along with a significant improvement in subjective feelings, patients noted positive dynamics. There are no complaints from patients in the control group.

\section{Conclusion}

Thus, the inclusion of the "asept" rinse aid, which has deodorizing and anti-inflammatory properties in the complex therapy of the initial manifestations of inflammation in the gums, had a positive effect on the subjective feelings of patients, as well as the normalization of the index assessment of hygiene, inflammation and bleeding of the gums.

\section{References:}

1. Aliev Z. U. Regional features of the prevalence of dental-facial anomalies in children // Bulletin of problems of biology and medicine. - 2012. - Vol. 2, No. 2. - Pp. 237-240.

2. Bulycheva E. A. Differentiated approach to the development of pathogenetic therapy of patients with temporomandibular joint dysfunction complicated by masticatory muscle hypertension: dis. ... doctor of medical Sciences : 14.00.14. - SPb, 2010. - 392 p.

3. Dmitrieva L. A. modern aspects of clinical Periodontology / L. A. Dmitrieva // M., - 2009. - 125C.

4. Elovikova T. M. Sialology in therapeutic dentistry /T. M. Elovikova, S. S. Grigoriev //Yekaterinburg: Publishing House"CIRCULATION". - 2018. -192s. M,1996.-122 s

5. Egorov P. M., Karapetyan I. S. Pain dysfunction of the temporomandibular joint. , Medicine publishing house

6. Kameneva L. A. Optimization of diagnostics and treatment of patients with the syndrome of pain dysfunction of the temporomandibular joint: dis. ...candidate of medical Sciences. Saratov state medical University, Saratov, 2014.

7. Lepilin A.V., Konnov V. V., Bagaryan E. A., Arushanyan A. R. clinical manifestations of pathology of temporomandibular joints and masticatory muscles in patients with disorders of occlusion of teeth and dentition // Saratov medical journal. 2010. Vol. 6 No. 2.- Pp. 405-409

. 8. Semenov R. R., Karpov S. M., Khatuaeva A. A., Karpov A. S. Etiological and pathogenetic mechanisms of formation of temporomandibular joint dysfunction. 2014.

9. Roberts M. V. dental health of children: where we are today and the remaining problems / M. V. Roberts // J. Clin. Pediatrician. Dent. - 2008. - Vol. 32, No. 3. - P. 231-234.

10. Gaffarov, A. S.,Saidov, A. A., the value of the matrix of metalloprotease in the pathology of 
temporomandibular joint in children // international journal for integrated education, Volume-3, issue-V, may 2020 65-68.

11. Saidov, A. A., Evaluation of several parameters of oral liquid at children with pathology of the temporomandibular joint // Asian journal of multidimensional research, Volume-09, issue-01 January 2020 59-63.

12. Irgashevich, D. A. (2020). Development of national network (tas-ix). ACADEMICIA: An International Multidisciplinary Research Journal, 10 (5), 144-151. 